\title{
Improve Sustainable Housing for People with Severe Mental and Drug Disorders. An Intervention Analysis of the Home-Treatment Service Providers in Vorarlberg/Austria
}

\author{
Nikolaus Blatter, Harald Rudolf Bliem, Silvia Blatter \\ University of Innsbruck, Faculty of Psychology and Sport Science, Innsbruck, Austria \\ Email: Nikolaus.Blatter@student.uibk.ac.at
}

How to cite this paper: Blatter, N., Bliem, H.R. and Blatter, S. (2019) Improve Sustainable Housing for People with Severe Mental and Drug Disorders. An Intervention Analysis of the Home-Treatment Service Providers in Vorarlberg/Austria. Open Journal of Social Sciences, 7, 396-412. https://doi.org/10.4236/jss.2019.74032

Received: March 24, 2019

Accepted: April 26, 2019

Published: April 29, 2019

Copyright $\odot 2019$ by author(s) and Scientific Research Publishing Inc. This work is licensed under the Creative Commons Attribution International License (CC BY 4.0).

http://creativecommons.org/licenses/by/4.0/

\begin{abstract}
Participants with mental or drug disorders and social needs have an increased risk to lose their flats because of the lack of an outpatient treatment. The current long-term study based on the C.O.M.E. program helps service providers in their care-work as well as clients to gain a more independent life. The sample involves 36 participants, from the age of 18 and older, which own a flat or have a lease contract. The innovation of the C.O.M.E. program is a weekly scored assessment-sheet which includes 13 items of self-determined housing issues. Regularly contacts on site between the caregivers and clients promote a sustainable relationship. Especially when the participant interrupts the contact or when symptoms worsening occurs it is indispensable to react in time and to ensure the continuous support. However, there are no findings that another long-term study with the same methodology has been conducted.
\end{abstract}

\section{Keywords}

C.O.M.E. Program, Weekly Measurements, Community Psychiatry, Mental Disorders, Home-Treatment

\section{Introduction}

In Europe, the Treatment First approach dominates the treatment of people with mental illness. This approach could be determined as a service provider-oriented treatment condition [1]. Otherwise, the Housing First approach is a client-led treatment condition in which the clients get treated more autonomous [2]. During the study of literature of the home-treatment research we detected that there 
is no procedure which uses weekly measurements for further analyses. The data of the outpatient treatment sector were collected over different measuring times. So we created the C.O.M.E. program to implement a procedure for weekly measurements. The following remarks should provide a common-sense of the home treatment situation in Austria and the Federal state Vorarlberg.

Austria has eight million habitants of which 15,000 people are homeless even though the country is a welfare state [1]. Most of them get unemployment or retirement money and additionally to their income a part or full-subsidy from the social-welfare department.

The Austrian social-report [2] detected that people who get a full-subsidy welfare benefit have similar multiple problems such as unemployment, no daily structure, less education, substance abuse, debt, no or less knowledge of the local language, poor state of physical and psychological health, precarious and insecure housing conditions, single parent and poor infrastructure in rural area. In Austria housing people with mental disorders and drug diagnosis depend on the availability of affordable housing. This vulnerable group often experiences a lack of treatment, health care service and community based integration. These circumstances are often favoured by poverty and homelessness [2].

In the year 2014 the policy in the federal state Vorarlberg in Austria agreed in consultation with the psychiatric service providers the implementation of the „psychiatric concept 2015-2025 “which contributes ten projects to improve the community psychiatry services. The implementation of the project number five, psychiatric home treatment service" started in the year 2015. The purpose of the "psychiatric home treatment service" is to facilitate the access to treatment, to decrease hospital admissions and to keep more people with mental and drug disorders staying in their own home [3].

The goal of the C.O.M.E. program is to support the service provider in their (daily) care-work and it detects if the individual-focused care supports clients to gain a life with more autonomy, increase permanent housing, decrease stays in hospital, improve a long-term mental stability and encourage them in the development of alternative assistance for mutual support. We assume that regular contacts lead to a stable psychopathology, which in turn influences positively the permanent housing, personal hygiene, household management and social activities.

\section{Theory}

The client-led approach corresponds to the requirements of the United Nations Convention on the Rights of Persons with Disabilities (CRPD). Our hypotheses derived from the two competing approaches Treatment First and Housing First and are based on the outcomes of our long-term study "Support Program for People with Mental Disorders to live a more independent life" [4] which was conducted from 2011-2014. This study enabled us to derive an approach which provides a basis for a practical instruction. 
Based on this theoretical foundation we developed the C.O.M.E. program which contains Choice-to-cooperation, Observation, Mutual-support and Evaluation. In this study we investigate the effect of the C.O.M.E. program on psycho-social stability and retain housing of people with severe mental and drugs disorders.

\subsection{Treatment First}

Treatment First is a stairway process. The clients are assisted through a structured process to determine goals and plans and to achieve step-by-step the housing readiness at the end of this process. The stairway model which meet the pre-requisitions that the clients are sobriety or treatment compliance is applied frequently in the treatment in Europe [5].

The program often misses the needs of people with mental illness, drug or alcohol problems and other complex needs because treatment and housing depend on abstinence and on the ability of the client to keep the rules of the Treatment First program [6]. There is a little range of consumer choice with regard to goals and plans but no exception in cases of alcohol or drug relapses [7]. This residential treatment demands an abstinence-based support.

The Treatment First condition is based on two assumptions:

- to teach the daily living skills to homeless adults it is necessary that they have a transitional or permanent housing and

- housing readiness is connected with sobriety and compliance with the (psychiatric) treatment.

If the clients agreed with the Treatment First conditions and adheres to the agreements on sobriety and on compliance, they complete the stages step-by-step and move on into a less restrictive residence. In cases of relapse or due non-compliance the client returns to a previous stage of restricted residence. The way to an independent life can be a long-lasting process for the service user [8]. Studies from Padgett [9] and Collins [10] have shown that an abstinence-based treatment condition is not more effective than Housing First programs.

\subsection{Housing First}

In the early 1990s this consumer driven approach was designed to provide a long-term support for people with complex needs [6]. Therefore the caregivers from the Pathway Inc. rented apartments from community landlords. They started to support people with severe mental illness and chronical homelessness.

The service users often had a poor physical health condition, suffered from drug abuse and learning disabilities. Furthermore, this people had a poor social condition such as unemployment, debt, homelessness and they experienced a lack of social support and community integration. These clients were supported to move directly in one of these apartments.

The Pathways program was named Housing First program. It distinguishes from other conventional supporting programs which demand a sobriety and 
compliance with the psychiatric treatment rules. The Housing First program is based on four theoretical principles [6]:

1) Immediate provision of housing and consumer-driven service.

2) Separation of housing and clinical service.

3) Providing support and treatment with a recovery orientation.

4) Facilitation of community integration.

Greenwood et al. [8] emphasized that mastery and perceived choice is another important factor for the client well-being and mental health stability.

According to the Housing First philosophy housing is a basic right. This right should apply to each person and it is not a reward at the end of a treatment condition. The Treatment First approach demands that clients have to achieve appointed goals before the service provider decides that the clients are "housing ready" [11].

However, the Housing First program separates housing from treatment support and contributes a secure leasing agreement. The consumer-driven support offers harm reduction and at least one on-site contact with a caregiver per month.

\subsection{C.O.M.E. Program}

The meaning of the abbreviation C.O.M.E. is Choice to cooperation, Observation, Mutual-support and Evaluation. From the two competing approaches Treatment First and Housing First we derived the C.O.M.E. program with the aim to enable the clients to live a more independent life. This non-abstinence approach promotes an individual need-oriented care by teaching social skills and social participation and by providing support in health-topics and everyday-matters. Housing and support are separated [11]. Furthermore, this program includes an assessment-sheet which reflects the topics of a self-determined housing. The assessment-sheet describes issues which often occur in home treatment situations.

One of the biggest challenges in the daily care of supportive housing is to keep the contact to the clients [8]. To handle this challenge it requires a stable cooperation-relationship between the clients and the caregivers. Our assumption of a sustainable relationship is built on three factors:

1) safety,

2) control and,

3) confidence.

Already at the beginning it is agreed that the service offer will be upheld even if the client relapse or reject it at times. Generally there will be one weekly face-to-face contact in the flat. The caregivers at least ensure the housing retention and react in time in cases of emergency. According to the needs of the clients and to the current situation there will be more or less contacts appointed. This procedure promotes control and autonomy of the clients. Moreover, the caregivers clarify that all issues and other topics are treated confidential.

The C.O.M.E. program approach involves a minimum willingness to cooperation between the service workforce (e.g. psychiatrists, psychologists, nurses), rel- 
atives, guardians and the clients of the program. Self and external observing during the process is also an important part of this program [12]. The mutual support as an unprofessional support can be useful in daily situations when the caregivers are not on site (e.g. support by neighbours). In cases of crisis it is necessary to meet the individual needs and therefore the caregiver has to respond flexibly and react in time (e.g. if the symptoms get worse or if conflicts occur) [13]. This requires that the caregivers have to evaluate and to reappraisal current situations and possibly to adjust the intervention to prevent a sudden interruption of the home-treatment support.

\section{Methods}

The long term study was considered as a naturalistic, quasi experimental design.

The individuals which were included in the study get benefit of the Department of community psychiatry and drughelp. The financial support of the department is necessary because these people cannot handle their own lives due to a psychiatric illness and/or drug addiction and therefore need chargeable support services. For the study the data of the probands were anonymized with alphanumeric encodings (e.g.: AKS05). For the analysis we use the data from the assessment sheet as well as from the WHODAS 2.0 and we also use the written report. The evaluation followed the criteria of the research of Willi Hager et al. [14]. The text below explains the further steps conducted during the study.

\subsection{Participants}

About 150 people are supported in the context of the community psychiatry home treatment service in Vorarlberg. 52 of them took part in our long-term study at the baseline in the year 2016. All of the probands, were able to provide informed consent and had a history of mental illness and were currently housed. Participants were drawn from the service providers to the long-term study and have to be at least 18 years old at the baseline. To reduce the loss at the beginning and during the data collection the caregiver of the service providers conduct the Interview and the ongoing measurements together with the probands. This procedure matches to the agreement and contents of the C.O.M.E. program-caregiver training. A total of 36 probands could be included into the further analysis. The age range was 20 to 68 years at the beginning of the study. The participants were both women $(\mathrm{N}=20)$ and men $(\mathrm{N}=16)$. In the case of a psychiatric and/or a drug diagnosis they get the social welfare benefit from the Government of Vorarlberg which covers the costs of the home-treatment-service. The participant requires a lease contract, own a home or have a use-permit from a service provider.

\subsection{Service Providers}

The federal state Vorarlberg counts 400,000 residents and is divided into four districts. In sum, four service providers ensure the community treatment service 
for people with mental health problems. One of the four service provider operates with use-permits. Among the rest three providers the service user needs a lease contract or an own home.

\subsection{Caregiver Training}

All of the participating caregivers had different education and practical experiences. In order to reduce the confounding variables of this heterogeneous group it was necessary to teach them the theoretical basics and the practical application of the assessment sheet and the WHODAS [15]. Therefore we contributed workshops for caregivers. One of the course content was to emphasize that a regular weekly scoring is as necessary as a related notice report for the data collection and its evaluation. Further we offered a troubleshooting and a coding-list. Another important point was that the caregivers accept that the participants decide the scope of service and that the caregivers have to work in a non-abstinence treatment condition (drugs, alcohol), comparable with the housing first principle [6].

\subsection{Psycho-Social Interview}

A sustainable supporting-cooperation is based on the three attitudes: safety, control and confidence. The client-led planning of interventions and goals take into consideration that the caregivers have to know the different stages of the participant's medical-history [13]. Therefore, we designed a psychosocial-interview according to Carlat's guidelines for anamnestic surveys of psychologists, social workers, nurses and psychiatric issues [16]. Demographic data include descriptive information of age, gender, education, employment and marital status. The history of housing and of illness, alcohol abuse and the drug history were assessed during a single interview. The demographic variables were also used for sample descriptions and for inferential statistical models. The descriptive data were processed using SPSS (Version 23).

\subsection{Assessment-Sheet}

In addition we used an assessment-sheet which was scored weekly for every participant. Each assessment-sheet contains 13 items which are related to the general steps and goals of the C.O.M.E. program and complies with four dimensions (as shown in Table 1):

- household management,

- personal hygiene,

- (social) participation,

- psychosocial stability.

The data were collected in the context of the home treatment service. There was no randomised controlled trial. The target groups pursued the same goals. Only the boundary-conditions were different (no lease contract, abstinent or not). Additionally, we use the caregivers report to interpret the weekly measurements.

Figure 1 shows the example of the assessment-sheet bringing more light 
Table 1. Type of items of the assessment-sheet.

\begin{tabular}{cc}
\hline Category & Item \\
\hline Household management & Home cleanliness \\
Trash \\
Grocery shopping \\
Nutrition \\
Personal hygiene & Body washing \\
& Laundry \\
(social) Participation & Daily Structure/Working \\
& Activities (social, community) \\
Psychosocial Stability & Medication (regular intake) \\
& Sleep habits \\
& Psychopathological state (drive, psychotic) \\
Dealing with drugs (alcohol, drugs) \\
Type of Contacts
\end{tabular}

\begin{tabular}{|l|l|l|l|l|l|l|l|}
\hline Houshold management & \multicolumn{1}{|l|}{ MO } & TU & WE & TH & FR & SA & SU \\
\hline Home cleanness & $\square$ & $\square$ & $\square$ & $\square$ & $\square$ & $\square$ & $\square$ \\
\hline Yes & $\square$ & $\square$ & $\square$ & $\square$ & $\square$ & $\square$ & $\square$ \\
\hline Partly & $\square$ & $\square$ & $\square$ & $\square$ & $\square$ & $\square$ & $\square$ \\
\hline No
\end{tabular}

\begin{tabular}{|l|c|l|l|l|l|l|l|}
\hline Trash & MO & TU & WE & TH & FR & SA & SU \\
\hline Yes & $\square$ & $\square$ & $\square$ & $\square$ & $\square$ & $\square$ & $\square$ \\
\hline Partly & $\square$ & $\square$ & $\square$ & $\square$ & $\square$ & $\square$ & $\square$ \\
\hline No & $\square$ & $\square$ & $\square$ & $\square$ & $\square$ & $\square$ & $\square$ \\
\hline
\end{tabular}

\begin{tabular}{|l|l|l|l|l|l|l|l|}
\hline Grocery shopping & MO & TU & WE & TH & FR & SA & SU \\
\hline Yes & $\square$ & $\square$ & $\square$ & $\square$ & $\square$ & $\square$ & $\square$ \\
\hline give guidance & $\square$ & $\square$ & $\square$ & $\square$ & $\square$ & $\square$ & $\square$ \\
\hline No & $\square$ & $\square$ & $\square$ & $\square$ & $\square$ & $\square$ & $\square$ \\
\hline
\end{tabular}

\begin{tabular}{|l|c|l|l|l|l|l|l|}
\hline Nutrition & MO & TU & WE & TH & FR & SA & SU \\
\hline Yes & $\square$ & $\square$ & $\square$ & $\square$ & $\square$ & $\square$ & $\square$ \\
\hline give guidance & $\square$ & $\square$ & $\square$ & $\square$ & $\square$ & $\square$ & $\square$ \\
\hline No & $\square$ & $\square$ & $\square$ & $\square$ & $\square$ & $\square$ & $\square$ \\
\hline
\end{tabular}

\begin{tabular}{|l|l|l|l|l|l|l|l|}
\hline Personal hygiene & MO & TU & WE & TH & FR & SA & SU \\
\hline Body washing & $\square$ & $\square$ & $\square$ & $\square$ & $\square$ & $\square$ & $\square$ \\
\hline Yes & $\square$ & $\square$ & $\square$ & $\square$ & $\square$ & $\square$ & $\square$ \\
\hline with motivation & $\square$ & $\square$ & $\square$ & $\square$ & $\square$ & $\square$ & $\square$ \\
\hline No
\end{tabular}

\begin{tabular}{|l|l|l|l|l|l|l|l|}
\hline (Doing the) laundry & MO & TU & WE & TH & FR & SA & SU \\
\hline Yes & $\square$ & $\square$ & $\square$ & $\square$ & $\square$ & $\square$ & $\square$ \\
\hline with motivation & $\square$ & $\square$ & $\square$ & $\square$ & $\square$ & $\square$ & $\square$ \\
\hline
\end{tabular}

\begin{tabular}{|l|l|l|l|l|l|l|l|}
\hline (social) Participation \\
\hline Daily Structure/Working & MO & TU & WE & TH & FR & SA & SU \\
\hline Yes/No need & $\square$ & $\square$ & $\square$ & $\square$ & $\square$ & $\square$ & $\square$ \\
\hline with Motivation & $\square$ & $\square$ & $\square$ & $\square$ & $\square$ & $\square$ & $\square$ \\
\hline No & $\square$ & $\square$ & $\square$ & $\square$ & $\square$ & $\square$ & $\square$ \\
\hline
\end{tabular}

\begin{tabular}{|l|c|c|c|c|c|c|c|}
\hline (social) Participation & MO & TU & WE & TH & FR & SA & SU \\
\hline Activities (social) & $\square$ & $\square$ & $\square$ & $\square$ & $\square$ & $\square$ & $\square$ \\
\hline Yes & $\square$ & $\square$ & $\square$ & $\square$ & $\square$ & $\square$ & $\square$ \\
\hline with Motivation & $\square$ & $\square$ & $\square$ & $\square$ & $\square$ & $\square$ & $\square$ \\
\hline No
\end{tabular}

\begin{tabular}{|c|c|c|c|c|c|c|c|}
\hline \multicolumn{8}{|l|}{ Psychosocial Stability } \\
\hline Medication (regular intake) & $\mathrm{MO}$ & TU & WE & $T H$ & FR & SA & SU \\
\hline Yes & $\square$ & $\square$ & $\square$ & $\square$ & $\square$ & $\square$ & $\square$ \\
\hline not like the medical prescription & $\square$ & $\square$ & $\square$ & $\square$ & $\square$ & $\square$ & $\square$ \\
\hline No & $\square$ & $\square$ & $\square$ & $\square$ & $\square$ & $\square$ & $\square$ \\
\hline Sleep habits & $\mathrm{MO}$ & TU & WE & $\mathrm{TH}$ & FR & SA & SU \\
\hline Yes & $\square$ & $\square$ & $\square$ & $\square$ & $\square$ & $\square$ & $\square$ \\
\hline with interruptions & $\square$ & $\square$ & $\square$ & $\square$ & $\square$ & $\square$ & $\square$ \\
\hline No sleep & $\square$ & $\square$ & $\square$ & $\square$ & $\square$ & $\square$ & $\square$ \\
\hline
\end{tabular}

\begin{tabular}{|l|l|l|l|l|l|l|l|}
\hline Psychopathological State & MO & TU & WE & TH & FR & SA & SU \\
\hline Stable & $\square$ & $\square$ & $\square$ & $\square$ & $\square$ & $\square$ & $\square$ \\
\hline Moderate (Cooperation is possible...) & $\square$ & $\square$ & $\square$ & $\square$ & $\square$ & $\square$ & $\square$ \\
\hline Instable (no cooperation is possible) & $\square$ & $\square$ & $\square$ & $\square$ & $\square$ & $\square$ & $\square$ \\
\hline
\end{tabular}

\begin{tabular}{|l|c|c|c|c|c|c|c|}
\hline Dealing with Drugs (Alcohol, drugs) & MO & TU & WE & TH & FR & SA & SU \\
\hline Stable & $\square$ & $\square$ & $\square$ & $\square$ & $\square$ & $\square$ & $\square$ \\
\hline Moderate (Cooperation is possible...) & $\square$ & $\square$ & $\square$ & $\square$ & $\square$ & $\square$ & $\square$ \\
\hline Instable (no cooperation is possible) & $\square$ & $\square$ & $\square$ & $\square$ & $\square$ & $\square$ & $\square$ \\
\hline
\end{tabular}

\begin{tabular}{|l|c|c|c|c|c|c|c|}
\hline Type of Contacts & MO & TU & WE & TH & FR & SA & SU \\
\hline No need & $\square$ & $\square$ & $\square$ & $\square$ & $\square$ & $\square$ & $\square$ \\
\hline Proband seeks Contact & $\square$ & $\square$ & $\square$ & $\square$ & $\square$ & $\square$ & $\square$ \\
\hline Cargiver stays in Contact & $\square$ & $\square$ & $\square$ & $\square$ & $\square$ & $\square$ & $\square$ \\
\hline Retreat & $\square$ & $\square$ & $\square$ & $\square$ & $\square$ & $\square$ & $\square$ \\
\hline
\end{tabular}

Report

Figure 1. Example of the assessment-sheet. 
how to use and how this tool is constructed. The items are divided into serval categories to make the changings of the probands during the home treatment contacts visible. The assessment-sheet is designed as a paper-pencil application.

Table 2 shows the factor analysis of the 13 item assessment-sheet confirmed the assignment of the items to 3 dimensions. The Kaiser-Meyer-Olkin (KMO) measure of the sample which suggested a minimum value of $\mathrm{KMO}=0.600$ to use the data for any further analysis was met. Values closer to $\mathrm{KMO}=1.000$ are better. The data from the current study has a KMO value which can be used for further analysis $(\mathrm{KMO}=0.814)$. The Bartlett-Test of Sphericity was significant $(\mathrm{p} \leq 0.001)$. The Bartlett-Test measures indicate that the correlation matrix is an identity matrix. All diagonal elements are 1 and all off diagonal elements are 0 . The two tests are a minimum standard which should be passed before a principal components analysis should be conducted. The extraction retained 3 factors which in sum explain $54.65 \%$ of the variance.

In addition, a Cronbach's alpha test was conducted. The Cronbach's alpha $(\alpha)$ is a measure of internal consistency, that is, how closely related a set of items are as a group. The measure is considered as the scale reliability. A value of $\alpha=0.70$ and higher is acceptable. The alpha coefficient for the 13 items is $\alpha=0.812$. A crucial part of the assessment sheet is to score the types of contacts between the participants and the caregivers because it is the basis for cooperation especially in crisis. The quality of contact can change through cooperation. The evaluation

Table 2. Rotated factor matrix of 13 items.

\begin{tabular}{|c|c|c|c|}
\hline \multicolumn{4}{|c|}{ Rotated Factor Matrix ${ }^{\mathrm{a}}$} \\
\hline & \multicolumn{3}{|c|}{ Factor } \\
\hline & 1 & 2 & 3 \\
\hline Home cleanness & 0.790 & & \\
\hline Trash & 0.776 & & \\
\hline Grocery shopping & 0.459 & & \\
\hline Nutrition & & & 0.568 \\
\hline Body washing & 0.791 & & \\
\hline Laundry & 0.647 & & \\
\hline Daily structure & & 0.764 & \\
\hline Social activities & & 0.715 & \\
\hline Psychopathological state & & 0.714 & \\
\hline Type of contacts & & 0.612 & \\
\hline Medication & & & 0.682 \\
\hline Sleep habits & & 0.427 & \\
\hline Dealing with drugs & & & 0.752 \\
\hline
\end{tabular}

Extraction Method: Principal Axis Factoring; Rotation Method: Varimax with Kaiser Normalizationa 
of the assessment-sheet item "Type of contacts" makes changes in contact-types visible. This item is splitted into four different scaling types (Table 3).

\subsection{World Health Organisation-Disability Assessment Schedule (WHODAS 2.0)}

The WHODAS is a generic cross cultures assessment instrument for health and disability. It corresponds to the requirements of International Classification of Functioning, Disability and Health (ICF). The scale includes mental, neurologi$\mathrm{cal}$ and addictive disorders and comprises six domains of functioning (Table 4).

The WHODAS is a well-studied schedule which captures the health difficulties over the past 30 days [15]. The plan includes 30 items. It takes about $20 \mathrm{mi}$ nutes to complete it and the plan is easy to handle. The caregivers have to use the WHODAS at the beginning and at the end of the home treatment service.

\section{Results}

\subsection{Descriptive Results}

Table 5 shows the characteristics of the probands. There is no correlation between the characteristics and the items of the assessment sheet.

The sample of 36 probands have an age average of 46.76 years $(S D=11.72)$. This long-term study includes $43.2 \%$ men and $56.8 \%$ women. The education level shows that most of the probands (52.8\%) have only a secondary school without further education. $36 \%$ of the probands completed a trainee program. Only $11.2 \%$ of the probands graduated a high school or a college. The marital status shows that 22 probands (61\%) are singles, two are married (5.6\%), eleven are divorced (30.6\%) and one is actually in a relationship.

Table 3. Types of contacts (assessment-sheet items).

\begin{tabular}{cc}
\hline Item & Scaling \\
\hline Type of Contacts & Retreat \\
& Caregiver stays in contact \\
Proband seeks contact \\
No need
\end{tabular}

Table 4. Domains and items of the WHODAS 2.0.

\begin{tabular}{cc}
\hline Domain & Items \\
\hline Cognition & Understanding and communicating \\
Mobility & Moving and getting around \\
Self-care-hygiene & Dressing, eating and staying alone \\
Getting along & Interacting with other people \\
Life activities & Domestic responsibilities, leisure, work and school \\
Participation & Joining in community activities \\
\hline
\end{tabular}


Table 5. Characteristics of the Probands showing an average age of 46.764 years, SD = 11.721, Range: 20 - 68 .

\begin{tabular}{|c|c|c|}
\hline Variable & $\mathbf{N}$ & $\%$ \\
\hline Gender & 36 & 100.0 \\
\hline Male & 16 & 43.2 \\
\hline Female & 20 & 56.8 \\
\hline \multicolumn{3}{|l|}{ Education } \\
\hline Primary school or less & 19 & 52.8 \\
\hline Trainee & 13 & 36.0 \\
\hline Completed highschool & 2 & 5.6 \\
\hline College (graduate degree) & 2 & 5.6 \\
\hline \multicolumn{3}{|l|}{ Marital status } \\
\hline Married & 2 & 5.6 \\
\hline Divorsed & 11 & 30.6 \\
\hline Single & 22 & 61.0 \\
\hline Relationship & 1 & 2.8 \\
\hline \multicolumn{3}{|l|}{ Income } \\
\hline Pension/Rehabilitation welfare & 32 & 88.8 \\
\hline Social-welfare & 3 & 8.4 \\
\hline Work & 1 & 2.8 \\
\hline \multicolumn{3}{|l|}{ Guardian } \\
\hline Yes & 7 & 19.4 \\
\hline No & 29 & 80.6 \\
\hline \multicolumn{3}{|l|}{ Diagnosis } \\
\hline Psychotic Disorder & 22 & 61.1 \\
\hline Depressive disorder & 7 & 19.4 \\
\hline Personality Disorder & 5 & 13.9 \\
\hline Substance use Disorder & 2 & 5.6 \\
\hline \multicolumn{3}{|c|}{$\begin{array}{l}\text { Last admission into psychiatric ward before include } \\
\text { into C.O.M.E. program }\end{array}$} \\
\hline No admission & 1 & 2.8 \\
\hline$<1$ year & 19 & 52.8 \\
\hline $1-5$ years & 12 & 33.3 \\
\hline $6-10$ years & 4 & 11.1 \\
\hline
\end{tabular}

The result of the income analysis is that 32 probands (88.8\%) gets a pension or rehabilitation welfare, three of the probands $(8.4 \%)$ get a social-welfare benefit and only one participant is an employer. Over $97 \%$ of the participants don't have any regular work or activity. In seven cases a guardian was appointed (19.4\%).

The analysis of the diagnoses shows that 22 probands suffer from psychotic 
disorder (61.1\%), seven persons suffer from depressive disorder (19.4), five probands suffers from personality disorder (13.9\%) and two probands have a substance use disorder (5.6\%). According to the medical history report $52.8 \%$ of the probands were admitted in a psychiatric ward within the last year, $33.3 \%$ during a period of one to five years.

\subsection{Relations between the Items: Spearman Correlation}

The further analysis was computed with the Spearman rank-order correlations $\left(r_{s}\right)$ of the 13 item of the assessment-sheet (Table 6). The result suggests that the correlation within all 13 items is high significant. $(\mathrm{p} \leq 0.001)$. The evaluation of the item psychopathological state shows a positive trend indicative of a stabilization of the associated items (Table 6). Except for the correlation between the items "Laundry/Medication" ( $\left.r s=0.069^{*} ; \mathrm{p}<0.05\right)$ there was a high significance on a $95 \%$ level $(\mathrm{p}<0.05)$. There was a nonsignificant correlation $\left(\mathrm{r}_{\mathrm{s}}=0.68 ; \mathrm{p}=\mathrm{n} . \mathrm{s}\right)$ between the items: "Dealing with Drugs/Home cleanness"; "Dealing with Drugs/Activities (social)"; "Activities (social)/Trash" and "Activities (social)/Medication". This is due to the circumstance that the items above are

Table 6. Spearman rank-order correlation (rs) of items of the assessment-sheet.
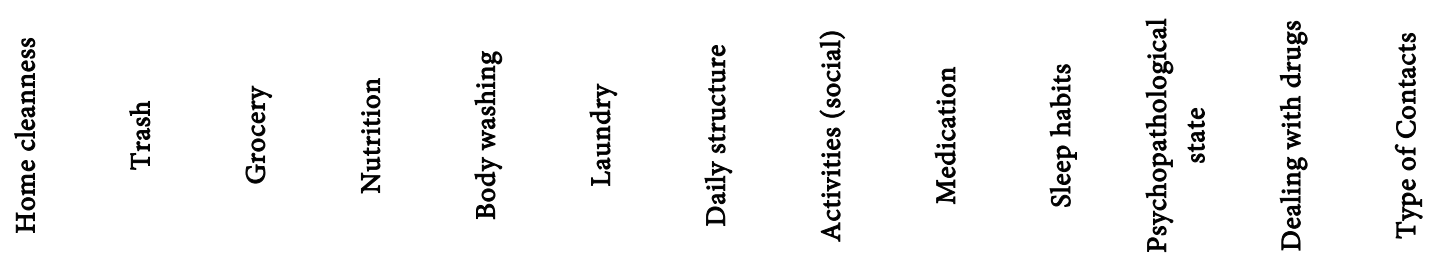

\begin{tabular}{|c|c|c|c|c|c|c|c|c|c|c|c|c|c|}
\hline $\begin{array}{c}\text { Home } \\
\text { cleanness }\end{array}$ & & $0.640^{* *}$ & $0.079^{* *}$ & $0.152^{\star *}$ & $0.498^{\star *}$ & $0.292^{* *}$ & $0.240^{\star *}$ & $0.117^{\star *}$ & $0.093^{* *}$ & $0.091^{* *}$ & $0.189^{* *}$ & 0.028 & $0.186^{\star *}$ \\
\hline Trash & $0.640^{* *}$ & & $0.141^{\star *}$ & $0.303^{\star *}$ & $0.457^{\star *}$ & $0.232^{\star *}$ & $0.108^{\star *}$ & -0.007 & $0.221^{\star *}$ & $0.113^{\star *}$ & $0.098^{\star *}$ & $0.183^{* \star}$ & $0.119^{* *}$ \\
\hline Grocery & $0.079^{* *}$ & $0.141^{\star *}$ & & $0.481^{\star \star}$ & $0.355^{\star *}$ & $0.426^{* *}$ & $0.222^{\star \star}$ & $0.424^{\star *}$ & $0.132^{\star *}$ & $0.235^{\star *}$ & $0.147^{\star \star}$ & $0.319^{* *}$ & $0.270^{\star \star}$ \\
\hline Nutrition & $0.152^{* *}$ & $0.303^{\star *}$ & $0.481^{\star *}$ & & $0.362^{\star \star}$ & $0.319^{\star *}$ & $0.316^{\star *}$ & $0.236^{\star *}$ & $0.211^{* *}$ & $0.295^{\star *}$ & $0.262^{\star *}$ & $0.349^{* *}$ & $0.211^{\star *}$ \\
\hline Body washing & $0.498^{* *}$ & $0.457^{* *}$ & $0.355^{\star *}$ & $0.362^{\star *}$ & & $0.499^{* *}$ & $0.288^{\star *}$ & $0.348^{\star *}$ & $0.100^{* *}$ & $0.142^{\star *}$ & $0.258^{\star *}$ & $0.088^{* *}$ & $0.250^{* *}$ \\
\hline Laundry & $0.292^{* *}$ & $0.232^{* *}$ & $0.426^{* *}$ & $0.319^{* *}$ & $0.499^{* *}$ & & $0.239^{* *}$ & $0.377^{* *}$ & $0.069^{*}$ & $0.144^{* *}$ & $0.100^{* *}$ & $0.136^{* *}$ & $0.328^{\star *}$ \\
\hline $\begin{array}{c}\text { Daily } \\
\text { structure }\end{array}$ & $0.240^{* *}$ & $0.108^{\star *}$ & $0.222^{\star *}$ & $0.316^{\star *}$ & $0.288^{\star \star}$ & $0.239^{* *}$ & & $0.412^{* *}$ & $0.126^{* *}$ & $0.222^{* *}$ & $0.494^{\star *}$ & $0.141^{* *}$ & $0.279^{* *}$ \\
\hline $\begin{array}{l}\text { Activities } \\
\text { (social) }\end{array}$ & $0.117^{\star *}$ & -0.007 & $0.424^{\star *}$ & $0.236^{\star *}$ & $0.348^{\star *}$ & $0.377^{\star *}$ & $0.412^{\star \star}$ & & 0.045 & $0.164^{\star *}$ & $0.285^{\star *}$ & 0.063 & $0.346^{* *}$ \\
\hline Medication & $0.093^{* *}$ & $0.221^{* *}$ & $0.132^{* *}$ & $0.211^{\star *}$ & $0.100^{\star *}$ & $0.069^{*}$ & $0.126^{\star *}$ & 0.045 & & $0.215^{\star *}$ & $0.164^{\star *}$ & $0.383^{* *}$ & $0.087^{\star *}$ \\
\hline Sleep habits & $0.091^{* *}$ & $0.113^{* *}$ & $0.235^{\star *}$ & $0.295^{\star *}$ & $0.142^{\star *}$ & $0.144^{\star *}$ & $0.222^{* *}$ & $0.164^{\star *}$ & $0.215^{\star *}$ & & $0.279^{* *}$ & $0.198^{* *}$ & $0.184^{\star *}$ \\
\hline $\begin{array}{l}\text { Psychopatholo } \\
\text { gical state }\end{array}$ & $0.189^{* *}$ & $0.098^{* *}$ & $0.147^{\star *}$ & $0.262^{\star *}$ & $0.258^{\star *}$ & $0.100^{* *}$ & $0.494^{\star *}$ & $0.285^{\star *}$ & $0.164^{* *}$ & $0.279^{* *}$ & & $0.215^{* *}$ & $0.264^{\star *}$ \\
\hline $\begin{array}{l}\text { Dealing with } \\
\text { drugs }\end{array}$ & 0.028 & $0.183^{* *}$ & $0.319^{* *}$ & $0.349^{* *}$ & $0.088^{* *}$ & $0.136^{* *}$ & $0.141^{\star *}$ & 0.063 & $0.383^{* *}$ & $0.198^{* *}$ & $0.215^{\star *}$ & & $0.088^{* *}$ \\
\hline $\begin{array}{l}\text { Type of } \\
\text { Contacts }\end{array}$ & $0.186^{* *}$ & $0.186^{*}$ & $0.270^{* *}$ & $0.211^{\star *}$ & $0.250^{* *}$ & $0.328^{* *}$ & $0.279^{* *}$ & $0.346^{* *}$ & $0.087^{* *}$ & $0.184^{* *}$ & $0.264^{* *}$ & $0.088^{* *}$ & \\
\hline
\end{tabular}

${ }^{*}$ high significant $(\mathrm{p} \leq 0.001)$ correlation; ${ }^{*}$ significant $(\mathrm{p} \leq 0.05)$. 
also not correlated within the rotated factor matrix (Table 2). The positive course of the other items reflects the increase in advisory contacts. Using the Cohen's guidelines, the effect size ranged from small $\left(r_{s}=0.10\right)$ to medium $\left(r_{s}=\right.$ 0.30) [17].

\subsection{Relations between the Items: Negative Spearman Correlation}

In some cases the loss of the flat or home is related to a decreased cleanness of the home. So the landlords or service providers could quit the lease contract. We assume that there is a relation between the items "Type of Contact", "Home-cleanness", "Psychopathological state" and "Dealing with drugs". The analysis of the assessment-sheet enable to show results which are related if e.g. drug or alcohol consume increase or contacts between the caregivers and clients decrease. The following analysis was conducted with only the categories in which the probands neglect the contacts ("Type of Contacts-retreat"), show symptom worsening ("Psychopathological state-instable"), increasing drug or alcohol consume ("Dealing with drugs-instable") and less scoring within the item "Home-cleanness". The results suggest that in case of less or no contacts the cleanness of the home decrease. The spearman correlation between the items "Home-cleanness" and "Type of Contacts-retreat" is high significant $\left(r_{s}=-0.382^{\star *} ; \mathrm{p} \leq 0.001\right)$. The spearman correlation between the items "Home-cleanness" and "Psychopathological state-instable" is high significant $\left(r_{s}=-0.740^{\star *} ; \mathrm{p} \leq 0.001\right)$. The spearman correlation of the item "Home-cleanness" and "Dealing with drugs-instable" show also a high significant result $\left(\mathrm{r}_{\mathrm{s}}=-0.357^{* *} ; \mathrm{p} \leq 0.001\right)$.

\subsection{Frequency of Coding the Items "Types of Contacts" and "Types of Psychopathological State"}

Figure 2 shows the frequency analysis of the item "Type of Contacts". It reveals a number of 1583 contacts between the caregivers and the participants and displays that in $39 \%$ the "Caregiver stays in contact" with the probands. In addition, $36 \%$ of coding this item belongs to the category "Proband seeks contact". In $21 \%$ of the cases there was "No need" and in 3\% of coding this item the probands retreat the contacts to the caregiver. Only $1 \%$ was an invalid coding.

Figure 3 shows the coded categories of the item "Types of Psychopathological State" in which the caregiver rates the state of the proband. The analysis counts 1350 codings. The categories are distributed as followed. The category "stable" was coded in $42.90 \%$, the "moderat" category was coded by the caregiver in $46.10 \%$ and in $9.60 \%$ of the cases the caregiver coded the "instable" category. In $1.40 \%$ there was an invalid coding. The spearman correlation between these two items as shown in Figure 2 and Figure 3 is high significant $\left(r_{s}=0.264, p \leq 0.001\right)$.

\subsection{Ordinal Regression}

In addition to the spearman rank-order correlation we use an ordinal regression to predict the variables which influences the stability of the psychopathological state which was used for the dependent variable. The independent variables are 


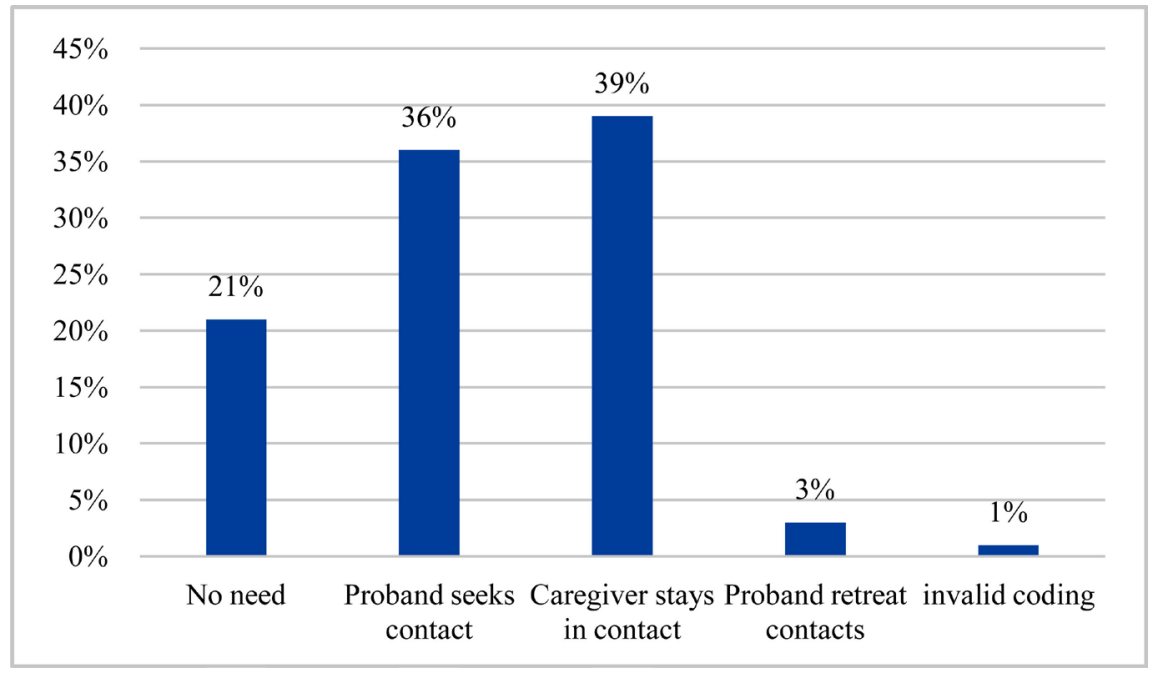

Figure 2. Frequency of coding the item "Types of Contacts".

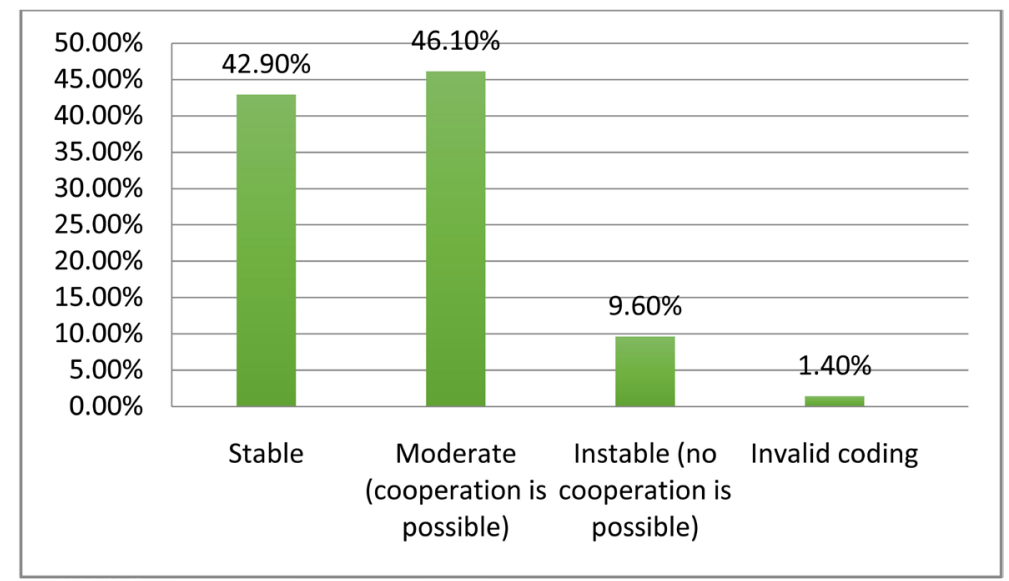

Figure 3. Frequency of coding the item "Types of Psychopathological State".

the categories of the assessment-sheet as shown in Figure 1. The ordinal regression is a member of the family of regression analyses. It describes data and explains the relationship between one dependent variable (psychopathological state) and two or more independent variables (Type of contacts, activity, sleep habits, daily structure, cleanness of the home and body washing). This is a predictive analysis. The 2-Log-Liklihood value was significant $(p<0.001)$ for the items of the assessment sheet. So we can assume that there is a significant improvement of the psychopathological state. The Nagelkerke pseudo was $\mathrm{R}^{2}=$ 0.39 (percentage of variance declared by ordinal regression). Further analysis show that the independent variables (items listed ${ }^{*}$ in Table 7) have a significant $(\mathrm{p}<0.05)$ effect to predict a stable psychopathological state.

Table 7 shows the independent variables which predict a stability of the psycho-pathological state on a $95 \%$ significance level.

The category "caregiver stays in/takes contact" of the item "Type of contacts" influences the psychopathological state in a positive direction. This category records the contact (face to face, telephone) which is initiated by the caregiver to 
Table 7. Ordinal regression-independent variables (categories of the items of the assessment-sheet).

\begin{tabular}{cc}
\hline Independent Variables & Significant $\mathrm{p}<0.05^{*}$ \\
\hline Contacts "caregiver stays in/takes contact" & $0.006^{*}$ \\
Contacts "proband seeks contact" & $0.007^{*}$ \\
Activity (social) with motivation/guidance intervention & $0.006^{*}$ \\
Sleep habits (no sleep) with intervention & $0.017^{*}$ \\
Sleep habits (with breaks) with intervention & $0.000^{*}$ \\
Daily structure (no need) & $0.000^{*}$ \\
Daily structure with motivation/guidance intervention & $0.000^{*}$ \\
Cleanness of the home with motivation/guidance intervention & $0.007^{*}$ \\
Body washing with motivation/guidance intervention & $0.047^{*}$ \\
Body washing with less motivation/guidance intervention & $0.031^{*}$ \\
\hline
\end{tabular}

prevent a symptom worsening, social withdrawal or other similar situations. The category "proband seeks contact" describe the initiative contact by the proband. The extended availability of the workforce during the day made it possible for the participants to react in time in cases of symptom worsening to call support from the caregiver.

Most of the other independent variables have a motivational or guidance content which results only from the contact with the caregivers. This points the importance of contacts between the probands and the clients, too.

\section{Discussion}

The present study starts to evaluate the C.O.M.E. program in 2016. The analysis of the support for people with mental disorders shows an effect by using the described program. It shows a connection between the types of contacts and the dimensions of the assessment-sheet. The strengths of the program are the weekly measurements which are related to the assessment-sheet. It is also possible to show relations if there is a lack of continuous contacts or symptom worsening. Furthermore this method of analysis also makes the lack of support visible. The results show the importance of the contact and also to stay in contact during symptom worsening. It is necessary to build a sustainable cooperation so both, caregiver and client, can react in time in cases of crisis. If the client refuses the contacts it is crucial that the workforce stays tuned until the client decides to go further with the treatment. This knowledge should be incorporated into the training of the caregivers. The results are related to the core of the C.O.M.E. program which takes in consideration the " $\mathrm{C}$ "-choice of cooperation between the clients and the caregivers which also is a criterion of the Housing First approach [6]. Furthermore, this choice is possible because of the separation from housing and service [6]. Otherwise, the clients which are treated within a Treatment First condition and not completely fit with this program maybe no longer 
get services from those service providers [7]. In addition, the "O"-Observation and "E"-Evaluation especially expresses the need of cooperation or contacts between the clients and the caregivers.

The analysis of the contact types "caregiver takes/stays in contact" and "proband seeks contact" indicate that these items are high significant predictors for the psychopathological stability. Another influencing factor was "contacts with motivational content" such as "activity (social)", doing the "daily structure", "apartment cleanness". These further hints refer to the importance of investing time in the treatment cooperation even if it only works on a low level, which can be shown on different low-level dimensions [8]:

- in terms of frequency contact,

- with regard to the implementation of the agreed activities,

- in terms of the extent of the support in the tasks or,

- in terms of intensity of contact (quality of cooperation).

For example, that the client stops the daily structure or is not willing to do the home cleanness and personal hygiene in cases of symptom worsening. Moreover, in time of symptom worsening it is important to shift the focus of support by reducing the treatment to the essentials. The focus must be limited to what is absolutely necessary, for example health aspects such as taking medication or participating in the daily structure.

In some situations, it is recommended to focusing only one or two topics during the treatment and neglect for instance the household management. To avoid client's refusal of the home treatment support it could make sense to make an agreement on "controlled harm reduction" which allows the participant to consume an agreed amount of alcohol or drugs. The different situations and the support have to be reflected regularly. This leads to the necessary flexibility in the support of people with mental health and drug disorders. The C.O.M.E. program allows the workforce to adjust the support and react in time. Symptom worsening can only be countered by rapid and flexible action without loss of contact.

Looking more closely at the sample, it must be noted that most of the participants had more admissions in the psychiatric ward when they were homeless. The results of the current study only included participants from the social psychiatry or drug help service providers.

In future times it makes sense to expand the C.O.M.E. program to the homeless treatment sector as well. This is the first study which utilise the approach of weekly coding the contacts and other categories which are related to the C.O.M.E program between the probands and the caregiver and bring more light to identify unmet needs and to provide people with mental and drug disorders a more independent life. The findings of the present study should not be overestimated. The assessment-sheet explains $54.65 \%$ of the variance. This is also a cue for the complexity of the psychiatric symptoms and to prevent a symptom worsening. 


\section{Conclusion}

Most of the participants have lost their homes due to difficult living conditions. Sometimes the lack of a professional home treatment service contributed that the worse condition was going on and subsequently this situation did not promote to trust any caregiver. The evaluation of the C.O.M.E. program is limited by the number of probands which are involved in this program. The findings suggested that the consumer driven approach and the associated choice for the probands (e.g. to stay in contact with the caregiver) decrease the psychiatric symptoms. The personal control which is also referred to the consumer driven approach can reduce the frustration by withdrawal of the service provider. On the other hand the service provider can stay tuned and react in time if the proband decided to go further with the support. The recent study is another contribution that the consumer driven support has to be more widely applied through the community psychiatry and has to be seen as an expansion of the support for the probands to meet the unmet needs in further times.

\section{Conflicts of Interest}

The authors declare no conflicts of interest regarding the publication of this paper.

\section{References}

[1] Lamei, N., Till, M., Glaser, T., Heuberger, R. and Göttlinger, S. (2017) Armut und sozial Ausgrenzung 2008 bis 2016. Statistik Austria, Wien.

[2] Bundesministerium für Arbeit, Soziales und Konsumentenschutz (2012) Sozialbericht 2011-2012. BMASK, Wien.

[3] Elgeti, H. (2014) Vorarlberger Psychiatriekonzept 2015-2015. Amt der Vorarlberger Landesregierung, Bregenz.

[4] Hausenbichl, N. (2016) Eine Langzeitstudie über die Analyse und Anwendung von Interventionsmaßnahmen für Menschen mit psychischen Störungen in einer betreuten Wohngemeinschaft einer Wohnungsloseneinrichtung, Master Thesis, Unversity of Innsbruck, Innsbruck.

[5] Johnsen, S. and Teixeira, L. (2010) Staircases, Elevators and Cycles of Change. Crisis, London.

[6] Tsemberis, S. (2010) Housing First. The Pathways Model to End Homelessness for People with Mental Illness and Addiction. Hazelden, Center City.

[7] Sahlin, I. (2002) The Staircase of Transition: Survival through Failure. Innovation, European Journal of Social Research, 18, 115-135.

[8] Greenwood, R.M., Schaefer-McDaniel, N.J., Winkel, G. and Tsemberis, S. (2005) Decreasing Psychiatric Symptoms by Increasing Choice in Services for Adults with Histories of Homelessness. American Journal of Community Psychology, 36, 223-238. https://doi.org/10.1007/s10464-005-8617-z

[9] Padgett, D. (2006) Housing First Services for People Who Are Homeless with Coocuiring Serious Mental Illness and Substance Abuse. Research on Social Work Practice, 16, 74-83. https://doi.org/10.1177/1049731505282593

[10] Collins, S.E., Malone, D.K., Clifasefi, S.L. and Ginzler, J.A. (2012) Project-Based 
Housing First for Chronically Homeless Individuals with Alcohol Problems: Within-Subjects Analyses of 2-Year Alcohol Trajectories. American Journal of Public Health, 102, 511-519. https://doi.org/10.2105/AJPH.2011.300403

[11] Goreing, P. and Tsemberis, S. (2014) Housing First ANS System/Community Transformation. In: Community Psychology and Community Mental Health, Oxford University Press, New York, 278-291. https://doi.org/10.1093/acprof:oso/9780199362424.003.0013

[12] Uchtenhagen, A. and Zieglgänsberger, W. (2000) Suchtmedizin. Urban \& Fischer, München.

[13] Wittchen, H.-U. and Hoyer, J. (2011) Klinische Psychologie und Psychotherapie 2. überarbeitete und werweiterte Auflage. Springer, Berlin. https://doi.org/10.1007/978-3-642-13018-2

[14] WHO World Health Organisation (2010) Disability Assessment Schedule 2.0 (WHO DAS 2.0). WHO Press, Geneva.

[15] Daniel, J.C. (2015) Das psychiatrische Gespräch. Hogrefe, Bern.

[16] Hager, W., Patry, J.-L. and Brezing, H. (2000) Evaluation pychologischer Interventionsmaßnahmen. Verlag Hans Huber, Bern.

[17] Cohen, J. (1988) Statistical Power Analysis for the Behavioal Sciences. Erlbaum, Hillsdale. 